\title{
Evolutionary Game Analysis of Government and Enterprises Carbon-Reduction based on Public Willingness
}

Guochang Fang ( $\sim$ fgchang79@163.com )

Nanjing University of Finance and Economics https://orcid.org/0000-0002-5922-3650

Yu He

Nanjing University of Finance and Economics

Lixin Tian

Nanjing Normal University

\section{Research Article}

Keywords: evolutionary game, public willingness, dynamic evolution path, stable strategy

Posted Date: July 12th, 2021

DOl: https://doi.org/10.21203/rs.3.rs-510883/v1

License: (c) (i) This work is licensed under a Creative Commons Attribution 4.0 International License.

Read Full License 


\section{Evolutionary Game Analysis of Government and Enterprises Carbon-Reduction}

(1)

${ }^{1}$ School of Economics, Nanjing University of Finance and Economics, Nanjing, Jiangsu, 210023,

China $;{ }^{2}$ School of Mathematical Sciences, Nanjing Normal University, Nanjing, Jiangsu 210023,

China

\section{Abstract}

This paper explores the evolutionary game of government and enterprises carbon-reduction with public willingness constraints. On the basis of the features of government and enterprises in energy saving and emission reduction system, the novel evolutionary game model is constructed.

The effects of behavioral strategy and willingness constraint strength are visualized by system dynamics theory. With the aid of these visual indicators, the varying dynamic evolution path under different situations is put forward. The economic interpretation of evolutionary stable strategies is discussed. The results show that, public willingness can promote government-enterprise to achieve the optimal state (action, carbon-reduction) spontaneously. The initial willingness can speed up the convergence rate of these two players' behaviors. The residents' willingness further restrains the behaviors of government and enterprises, which can eliminate the possibility of adopting passive strategies and reduce the lag of strategies for both parties.

Key words: evolutionary game; public willingness; dynamic evolution path; stable strategy

\section{Introduction}

*Corresponding author. Tel.: +86 (025) 84028202; fax: +86 (025) 84028202.E-mail addresses: fgchang79@163.com (G. Fang). 
ecological imbalance and other problems are profoundly affecting the process of human civilization. The mainstream believes that greenhouse gas emissions from human activities are the main cause of global warming (Rosa and Dietz 2012). There was a long and arduous negotiation between international communities in order to control greenhouse gas emissions. It has successively reached such landmark international conventions as the United Nations Framework Convention on climate change, the Kyoto Protocol and the Paris Agreement. In the development and implementation of these conventions, people come to realize that energy saving and emission reduction (ESER) is the only way to deal with global warming (Jiao et al. 2021). The smooth implementation of ESER cannot be separated from the correct leadership of government. As a matter of fact, no country is immune to the complex and multiple climate problems in the world. Consequently it is very important to formulate ESER policies according to national conditions.

As the main source of carbon emissions, enterprises are the key actors in ESER (Yu et al. 2019). However, in reality, the number of enterprise that takes the initiative to take measures to reduce carbon emissions is relatively small. The main reasons for this phenomenon lie in government's inaction, enterprises' pursuit of short-term profit maximization, and weak public environmental awareness (Liu 2012). Both enterprise emission reduction and government regulation have to pay appropriate costs (Zhou et al. 2016). As the main driving force of ESER, government should actively supervise and guide enterprises' emission reduction behavior (Peters et al. 2010). Rational enterprises will identify policy orientation and decide whether to carry out ESER according to the principle of profit maximization. Conversely, enterprise behavior can also affect government decision-making (Price et al. 2010). ESER process will be promoted in the game between government and enterprises. Due to the mutual influence and restriction between 
government and enterprises (Zhu and Dou, 2007), the research on these two subjects is exceptionally important.

Stackelberg game, Bayesian game, non cooperative game and other classical game theories (Wang et al. 2017; Zu et al. 2018; Zhao et al. 2015) are widely used in the study of the mechanism between government and enterprises. Classical game theory requires a basic hypothesis of 'complete rationality', and in terms of the degree of rationality, the requirement of complete rationality is higher than that of "rational economic man hypothesis" in neoclassical economics (Kreps, 1990). However, in real life, complete rationality is only an ideal state, and reasoning errors in economic decision-making are inevitable. Factors such as insufficient consideration, information cost, excitement and experience will lead to inaccurate and irrational decision-making of government and enterprises (Nelson, 2009). Therefore, evolutionary game based on bounded rationality has more practical significance.

Existing research based on evolutionary game model shows that, appropriate low-carbon subsidies, reasonable carbon taxes (Zhao et al. 2016; Li et al. 2019) and a dynamic combination of these two measures (Chen and Hu 2018; Wang and Shi 2019) are conducive to the smooth development of ESER. The improvement of legal restriction, strengthen of supervision (Peng et al. 2019) and dilution of emission reduction costs (Shuai et al. 2019; Fan et al. 2017) can encourage both government and enterprises to be more proactive in ESER. The influence of third-party factors cannot be ignored. The increase in green consumers (Wang and Zheng 2019) and the diffusion of low-carbon preferences (Fan and Dong 2018) could promote the formation and development of low-carbon markets. Then the production enterprises will be forced to adopt low-carbon strategies. The application of two-population evolutionary game (Mahmoudi and 
Rasti-Barzoki 2018) optimizes the objective function of government and enterprises, which is a beneficial exploration of the relationship between the two subjects in ESER.

The above studies have analyzed the interaction mechanism and influencing factors between government and enterprises on emission reduction issues from different perspectives, and have conducted a beneficial discussion on the optimal path of carbon-reduction. The introduction of appropriate constraints (Peng et al. 2019) can make the results of government-enterprise game easier to achieve the optimal state. In reality, the important role of public willingness in ESER cannot be ignored (Hårsman and Quigley 2010; Li et al. 2020). Therefore, the introduction of public willingness is closer to the reality, and it will also be beneficial to improve the outcome of government-enterprise game.

Previous researches mostly limited to the interaction between government and enterprises' behavioral strategies. The description of the evolution path was not detailed enough, and there was no economic meaning interpretation of the evolution equilibrium results. In this paper, we consider the game between government and enterprises under the premise of bounded rationality. Based on evolutionary game model and system dynamics method, dynamic evolution paths in various situations are obtained. The evolutionary stable strategies of these two players are analyzed. The economic implications of evolutionary stable results are discussed. By introducing public willingness into the game between government and enterprises, the analysis framework of government-enterprise game is effectively expanded. The influence of factors such as initial strategy and willingness constraint on the behavioral strategy of both players is visualized, which makes the analysis more vivid and easy to accept.

The rest of this paper is organized as follows. Section 2 establishes the evolutionary game 
model with public willingness constraints. Section 3 is about a scenario analysis. Policy recommendations are presented in Section 4. Conclusions and prospects are discussed in Section 5.

\section{Methodology}

The game results of government and enterprises in ESER system directly affect the process and implementation effect of ESER. For rational government and enterprises, effective governments will formulate relevant policies based on ESER plans to guide enterprises to reduce emissions. Enterprises can choose the path of carbon-reduction designated by government, or they may evade it. Government will adjust the policy measures after receiving feedback from enterprises, and enterprises will make corresponding response after measuring the gains and losses. Theoretically, government and enterprises have their own ideal strategic choices in the above circumstances, unless there are other variables to interfere (such as public willingness). Based on this, this paper puts forward the following assumptions for the model:

(1) Suppose that two players of the game are local government and enterprises, and both parties have complete information about basic structure and rules of the game. Both sides are free to choose their own behavior strategies in carbon emission reduction. Enterprises have two choices: carbon-reduction and no reduction. We can use CR to indicate the enterprise's carbon-reduction strategy, and NR to indicate the enterprise's strategy of no reduction. Government has two choices for carbon-reduction: Action and Inaction. We can use AC to express the government's action strategy and NA to express the government's inaction strategy.

(2) When enterprises adopt CR strategy, they will get more benefits from the optimization of production process, the improvement of product quality and the improvement of enterprise 
reputation. At this time, the comprehensive income of enterprises is recorded as $R_{1}$. At the same time, it can not be ignored that enterprises need to pay the corresponding cost to take emission reduction measures, which is recorded as $C_{1}$. On the contrary, if the enterprise chooses NR, it will not be able to obtain relevant additional income, and the comprehensive income of the enterprise is recorded as $R_{2}$. And $R_{1}$ is necessarily greater than $R_{2}$.

(3) For the government, the behavior of enterprises in carbon emission reduction will inevitably affect the overall social welfare. Enterprises take CR measures, which is conducive to the improvement of the ecological environment and low-carbon awareness, will inevitably enhance social benefits, and social benefits will eventually turn into government achievements. Therefore, when enterprises adopt CR strategy, the government's social benefits are recorded as $U_{1}$. When enterprises adopt NR strategy, the government's social benefits are recorded as $U_{2}$. And $U_{1}$ is necessarily greater than $U_{2}$.

(4) The government's 'AC' includes positive and negative regulation of enterprises. Positive regulation means that when enterprises take effective measures to reduce emissions, the government gives subsidies in time to improve the enthusiasm of CR. Such subsidies are recorded as $S$. Negative regulation means that the government takes decisive punishment measures to weaken the motivation of enterprises to adopt negative strategies when enterprises are negative in CR. Such punishment are recorded as $F$. In addition, it is worth noting that when the government adopts AC strategy, it must pay human and material resources to supervise the enterprises, and it also needs to formulate written reward and punishment policies. Therefore, the government's AC cost is recorded as $C_{2}$.

(5) There is no extra cost for the government and enterprises when they do not take measures, 
and it is assumed that the above parameters are greater than zero.

The payoff matrix of government and enterprises is shown in Table 1 and table 2.

\section{Table 1}

135 The government revenues under different enterprise behaviors.

\begin{tabular}{|c|c|c|c|c|}
\hline Enterprise behavior & \multicolumn{2}{|c|}{$\mathrm{CR}(y)$} & \multicolumn{2}{|c|}{$\mathrm{NR}(1-y)$} \\
\hline Government behavior & $\mathrm{AC}$ & NA & $\mathrm{AC}$ & NA \\
\hline Government revenue & $U_{1}-C_{2}-S$ & $U_{1}$ & $U_{2}-C_{2}+F$ & $U_{2}$ \\
\hline
\end{tabular}

\section{Table 2}

137 The enterprise profits under different government behaviors.

\begin{tabular}{ccccc}
\hline Government behavior & \multicolumn{2}{c}{$\mathrm{AC}(x)$} & & $\mathrm{NA}(1-x)$ \\
\hline Enterprise behavior & $\mathrm{CR}$ & $\mathrm{NR}$ & $\mathrm{CR}$ & $\mathrm{NR}$ \\
Enterprise profit & $R_{1}-C_{1}+\mathrm{S}$ & $R_{2}-F$ & $R_{1}-C_{1}$ & $R_{2}$ \\
\hline
\end{tabular}

It is assumed that the probability of CR is $y$ and $1-y$ for $\mathrm{NR}(0 \leq y \leq 1)$; the probability of AC is

The expected return of $\mathrm{AC}$ is recorded as $E_{11}$, and the expected return of NA is recorded as $E_{12}$. According to the payoff matrix, the expected return of government's choice for AC and NA

142 are respectively $E_{11}=\mathrm{y}\left(U_{1}-C_{2}-\mathrm{S}\right)+(1-\mathrm{y})\left(U_{2}-C_{2}+\mathrm{F}\right), E_{12}=y U_{1}+(1-y) U_{2}$. The

143 average expected return of government is $\overline{E_{1}}=x E_{11}+(1-x) E_{12}$. According to the Malthusian equation (Friedman, 1991), the growth rate of the proportion of government groups choosing 'AC'

145 strategy over time is $d_{x} / d_{t}$. And $d_{x} / d_{t}$ is proportional to the difference of the expected return and average expected return of 'AC' strategy. From this, we can get the dynamic evolution of the behavior is : 


$$
F(x)=\frac{d_{x}}{d_{t}}=x\left(E_{11}-\overline{E_{1}}\right)=x(1-x)\left[F-C_{2}-y(S+F)\right]
$$

The expected return of $\mathrm{CR}$ is recorded as $E_{21}$, and the expected return of NR is recorded as $E_{22}$. According to the payoff matrix, the expected return of enterprises' choice for CR and NR are respectively $\quad E_{21}=x\left(R_{1}-C_{1}+S\right)+(1-x)\left(R_{1}-C_{1}\right), E_{22}=x\left(R_{2}-F\right)+(1-x) R_{2} . \quad$ The average expected return of enterprises is $\overline{E_{2}}=x E_{21}+(1-x) E_{22}$. The replication dynamic equation of enterprise behavior is as follows:

$$
\mathrm{F}(y)=\frac{d_{y}}{d_{t}}=y\left(E_{21}-\overline{E_{2}}\right)=y(1-y)\left[x(S+F)+R_{1}-C_{1}-R_{2}\right]
$$

enterprises can form a two-dimensional dynamic system:

$$
\left\{\begin{array}{l}
F(x)=\frac{d_{x}}{d_{t}}=x(1-x)\left[F-C_{2}-y(S+F)\right] \\
F(y)=\frac{d_{y}}{d_{t}}=y(1-y)\left[x(S+F)+R_{1}-C_{1}-R_{2}\right]
\end{array}\right.
$$

In order to find the equilibrium point of evolutionary game, let $F(x)=0, F(y)=0$, we can get several possible stable points: $x_{0}=\frac{C_{1}+R_{2}-R_{1}}{S+F}, x_{1}=0, x_{2}=1$ and $y_{0}=\frac{F-C_{2}}{S+F}, y_{1}=0, y_{2}=$ exists when $x_{0} \in[0,1], y_{0} \in[0,1]$. J as:

$$
\mathrm{J}=\left[\begin{array}{ll}
\frac{d F(x)}{d x} & \frac{d F(x)}{d y} \\
\frac{d F(y)}{d x} & \frac{d F(y)}{d y}
\end{array}\right]=\left[\begin{array}{ll}
a & b \\
c & d
\end{array}\right]
$$




$$
=\left[\begin{array}{cc}
(1-2 x)\left[F-C_{2}-y(S+F)\right] & x(x-1)(S+F) \\
y(1-y)(S+F) & (1-2 y)\left[x(S+F)+R_{1}-C_{1}-R_{2}\right]
\end{array}\right]
$$

Table 3

Values at the local equilibrium point

\begin{tabular}{ccccc}
\hline Equilibrium point & $a$ & $b$ & $c$ & $d$ \\
\hline$(0,0)$ & $F-C_{2}$ & 0 & 0 & $R_{1}-C_{1}-R_{2}$ \\
$(0,1)$ & $-C_{2}-S$ & 0 & 0 & $-\left(R_{1}-C_{1}-R_{2}\right)$ \\
$(1,0)$ & $-\left(F-C_{2}\right)$ & 0 & 0 & $S+F+R_{1}-C_{1}-R_{2}$ \\
$(1,1)$ & $C_{2}+S$ & 0 & 0 & $-\left(S+F+R_{1}-C_{1}-R_{2}\right)$ \\
$\left(x_{0}, y_{0}\right)$ & 0 & $X$ & $Y$ & 0 \\
\hline
\end{tabular}
requirements for environmental quality improvement are getting higher and higher. This also puts forward brand-new requirements for the two important subjects (government and enterprises) in the emission reduction work. This article believes that public willingness mainly contains three levels of connotation: First, the impact of residents' willingness on enterprises. If enterprises do not adopt CR strategy, casusing excessive carbon emissions, the public will form negative opinion 
on enterprises, resulting in the loss of enterprise reputation and the decline of stock price (enterprises with large carbon emissions are generally listed companies). And in the long run, it will affect the overall performance of enterprises. The second is the influence of residents' willingness on the government. If government does not effectively supervise and restrict enterprises that exceed carbon emissions, residents will question government's ruling ability, reduce the "loyal investment" to the government, and affect government's credibility. Finally, what is more special is that the willingness of enterprises also has a certain impact on the government. Although enterprises are a powerful group relative to the public, they are both managed objects relative to the government. Therefore, enterprises can be regarded as a part of the "public". The development of enterprises is inseparable from the support of relevant policy and subsidies. If enterprises respond to the call of government to actively ESER, but the government is indifferent and does not provide assistance to it, enterprises will also have opinions on government's inaction and protest to the government in various ways.

In this situation, the payoff matrix of government and enterprises will change accordingly. Assuming that government has no action to give enterprises corresponding carbon-reduction subsidies, enterprises will appeal and lobby to the government. At this time, the coordination cost and possible compensation loss of government are recorded as $D_{1}$. $D_{1}$ It can also be regarded as the constraint of enterprises' willingness on the government. If enterprises do not reduce emissions, regardless of government's action or inaction, the negative evaluation of residents will bring brand and reputation losses to enterprises, which is recorded as $D_{2} . D_{2}$ can also be regarded as the constraint of residents' willingness on enterprises. If both government and enterprises do not make a difference in carbon-reduction, not only do enterprises lose their brand and reputation, but the 

are greater than zero).

The new payoff matrix of government and enterprises is shown in Table 4 and table 5.

\section{Table 4}

The government revenues under different enterprise behaviors (public willingness).

\begin{tabular}{ccccc}
\hline Enterprise behavior & \multicolumn{2}{c}{$\mathrm{CR}(y)$} & \multicolumn{2}{c}{$\mathrm{NR}(1-y)$} \\
\hline Government behavior & $\mathrm{AC}$ & $\mathrm{NA}$ & $\mathrm{AC}$ & $\mathrm{NA}$ \\
Government revenue & $U_{1}-C_{2}-\mathrm{S}$ & $U_{1}-D_{1}$ & $U_{2}-C_{2}+\mathrm{F}$ & $U_{2}-D_{3}$ \\
\hline
\end{tabular}

\section{Table 5}

217 The enterprise profits under different government behaviors (public willingness).

Government behavior $\quad \mathrm{AC}(x) \quad \mathrm{NA}(1-x)$

\begin{tabular}{ccccc}
\hline Enterprise behavior & $\mathrm{CR}$ & $\mathrm{NR}$ & $\mathrm{CR}$ & $\mathrm{NR}$ \\
Enterprise profit & $R_{1}-C_{1}+\mathrm{S}$ & $R_{2}-F-D_{2}$ & $R_{1}-C_{1}$ & $R_{2}-D_{2}$
\end{tabular}

$$
\left\{\begin{array}{c}
\mathrm{F}(x)=\frac{d_{x}}{d_{t}}=x(1-x)\left[F-C_{2}+D_{3}-y\left(S+F+D_{3}-D_{1}\right)\right] \\
\mathrm{F}(y)=\frac{d_{y}}{d_{t}}=y(1-y)\left[x(S+F)+R_{1}-C_{1}-R_{2}+D_{2}\right]
\end{array}\right.
$$

$$
\mathrm{J}^{\prime}=\left[\begin{array}{ll}
a^{\prime} & b^{\prime} \\
c^{\prime} & d^{\prime}
\end{array}\right]=
$$


(1) When $F-C_{2}+D_{3}<0, R_{1}-C_{1}-R_{2}+D_{2}<0$, the evolutionary stable strategy (ESS) of system exists (NA, NR).

(2) When $D_{1}-C_{2}-S<0, R_{1}-C_{1}-R_{2}+D_{2}>0$, the ESS of system is (NA, CR).

(3) When $F-C_{2}+D_{3}>0, R_{1}-C_{1}-R_{2}+D_{2}<-(S+F)$, the ESS of system is (AC, NR).

(4) When $D_{1}-C_{2}-S>0, R_{1}-C_{1}-R_{2}+D_{2}>-(S+F)$, the ESS of system exists (AC, CR).

(5) When $F-C_{2}+D_{3}>0, D_{1}-C_{2}-S<0$ and $-(S+F)<R_{1}-C_{1}-R_{2}+D_{2}<0$, There

\section{Proof}

Table 6

Values at the local equilibrium point (public willingness)

\begin{tabular}{ccccc}
\hline Equilibrium point & $a^{\prime}$ & $b^{\prime}$ & $c^{\prime}$ & $d^{\prime}$ \\
\hline$(0,0)$ & $F-C_{2}+D_{3}$ & 0 & 0 & $R_{1}-C_{1}-R_{2}+D_{2}$ \\
$(0,1)$ & $-C_{2}-S+D_{1}$ & 0 & 0 & $-\left(R_{1}-C_{1}-R_{2}+D_{2}\right)$ \\
$(1,0)$ & $-\left(F-C_{2}+D_{3}\right)$ & 0 & 0 & $S+F+R_{1}-C_{1}-R_{2}+D_{2}$ \\
$(1,1)$ & $C_{2}+S-D_{1}$ & 0 & 0 & $-\left(S+F+R_{1}-C_{1}-R_{2}+D_{2}\right)$ \\
$\left(x_{0}{ }^{\prime}, y_{0}{ }^{\prime}\right)$ & 0 & $\mathrm{X}^{\prime}$ & $\mathrm{Y}^{\prime}$ & 0
\end{tabular}

$\left.R_{2}-D_{2}\right) /(S+F), y_{0}{ }^{\prime}=\left(F+D_{3}-C_{2}\right) /\left(S+F+D_{3}-D_{1}\right)$.

(1) $F-C_{2}+D_{3}<0, D_{1}-C_{2}-S<0,-(S+F)<R_{1}-C_{1}-R_{2}+D_{2}<0$. 
(2) $F-C_{2}+D_{3}<0, D_{1}-C_{2}-S<0, R_{1}-C_{1}-R_{2}+D_{2}>0$.

(3) $F-C_{2}+D_{3}<0, D_{1}-C_{2}-S<0, R_{1}-C_{1}-R_{2}+D_{2}<-(S+F)$.

(4) $F-C_{2}+D_{3}<0, D_{1}-C_{2}-S>0,-(S+F)<R_{1}-C_{1}-R_{2}+D_{2}<0$.

(5) $F-C_{2}+D_{3}<0, D_{1}-C_{2}-S>0, R_{1}-C_{1}-R_{2}+D_{2}>0$.

(6) $F-C_{2}+D_{3}<0, D_{1}-C_{2}-S>0, R_{1}-C_{1}-R_{2}+D_{2}<-(S+F)$.

(7) F $-C_{2}+D_{3}>0, D_{1}-C_{2}-S<0,-(S+F)<R_{1}-C_{1}-R_{2}+D_{2}<0$.

(8) $F-C_{2}+D_{3}>0, D_{1}-C_{2}-S<0, R_{1}-C_{1}-R_{2}+D_{2}>0$.

$$
\text { (9) } F-C_{2}+D_{3}>0, D_{1}-C_{2}-S<0, R_{1}-C_{1}-R_{2}+D_{2}<-(S+F) \text {. }
$$

$$
\text { (10) } F-C_{2}+D_{3}>0, D_{1}-C_{2}-S>0,-(S+F)<R_{1}-C_{1}-R_{2}+D_{2}<0 \text {. }
$$$$
\text { (11) } F-C_{2}+D_{3}>0, D_{1}-C_{2}-S>0, R_{1}-C_{1}-R_{2}+D_{2}>0 \text {. }
$$

$$
\text { (12) } F-C_{2}+D_{3}>0, D_{1}-C_{2}-S>0, R_{1}-C_{1}-R_{2}+D_{2}<-(S+F) \text {. }
$$

By analyzing the symbols of determinant and trace in Jacobian matrix under different cases and no evolutionary stable point in case (7). Then Proposition 1 can be proved.

\section{Table 7}

Local stability of equilibrium point in various cases (public willingness)

\begin{tabular}{cccccccccc}
\hline \multirow{2}{*}{$\begin{array}{c}\text { Equilibrium } \\
\text { points }\end{array}$} & \multicolumn{3}{c}{ case(1) } & \multicolumn{3}{c}{ case(2) } \\
\cline { 2 - 9 } & $\operatorname{Det}(\mathrm{J})$ & $\operatorname{Tr}(\mathrm{J})$ & state & $\operatorname{Det}(\mathrm{J})$ & $\operatorname{Tr}(\mathrm{J})$ & state & $\operatorname{Det}(\mathrm{J})$ & $\operatorname{Tr}(\mathrm{J})$ & state \\
\hline$(0,0)$ & + & - & ESS & - & $\mathrm{N}$ & Saddle point & + & - & ESS \\
$(0,1)$ & - & $\mathrm{N}$ & Saddle point & + & - & ESS & - & $\mathrm{N}$ & Saddle point
\end{tabular}




\begin{tabular}{|c|c|c|c|c|c|c|c|c|c|}
\hline$(1,0)$ & + & + & Instability point & + & + & Instability point & - & $\mathrm{N}$ & Saddle point \\
\hline$(1,1)$ & - & $\mathrm{N}$ & Saddle point & - & $\mathrm{N}$ & Saddle point & + & + & Instability point \\
\hline$\left(x_{0}{ }^{\prime}, y_{0}{ }^{\prime}\right)$ & & & less & & & & & & \\
\hline
\end{tabular}

263

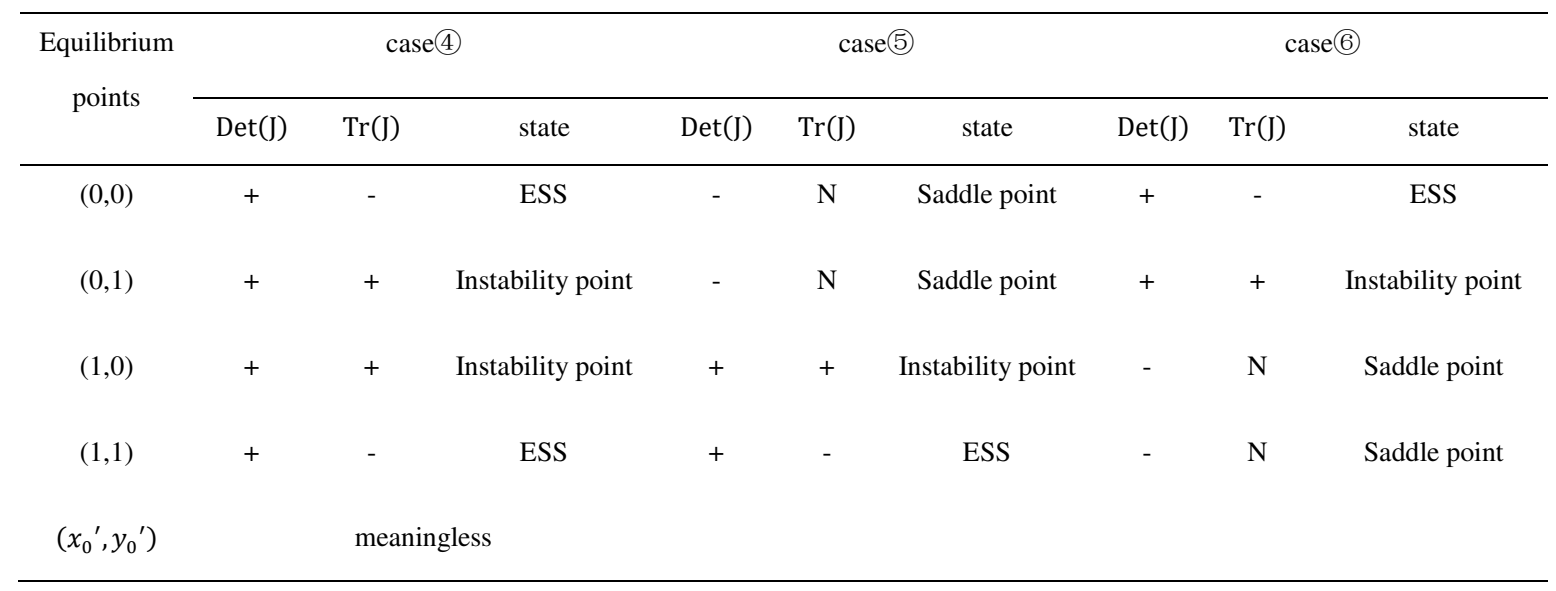

264

\begin{tabular}{|c|c|c|c|c|c|c|c|c|c|}
\hline \multirow{2}{*}{$\begin{array}{c}\text { Equilibrium } \\
\text { points }\end{array}$} & \multicolumn{3}{|c|}{ case 7} & \multicolumn{3}{|c|}{ case (8) } & \multicolumn{3}{|c|}{ case (9) } \\
\hline & $\operatorname{Det}(J)$ & $\operatorname{Tr}(\mathrm{J})$ & state & $\operatorname{Det}(J)$ & $\operatorname{Tr}(J)$ & state & $\operatorname{Det}(J)$ & $\operatorname{Tr}(J)$ & state \\
\hline$(0,0)$ & - & $\mathrm{N}$ & Saddle point & + & + & Instability point & - & $\mathrm{N}$ & Saddle point \\
\hline$(0,1)$ & - & $\mathrm{N}$ & Saddle point & + & - & ESS & - & $\mathrm{N}$ & Saddle point \\
\hline$(1,0)$ & - & $\mathrm{N}$ & Saddle point & - & $\mathrm{N}$ & Saddle point & + & - & ESS \\
\hline$(1,1)$ & - & $\mathrm{N}$ & Saddle point & - & $\mathrm{N}$ & Saddle point & + & + & Instability point \\
\hline$\left(x_{0}{ }^{\prime}, y_{0}{ }^{\prime}\right)$ & + & 0 & Central point & & & & & & \\
\hline
\end{tabular}

265

\begin{tabular}{|c|c|c|c|c|c|c|c|c|c|}
\hline \multirow{2}{*}{$\begin{array}{l}\text { Equilibrium } \\
\text { points }\end{array}$} & \multicolumn{3}{|c|}{ case10 } & \multicolumn{3}{|c|}{ case11 } & \multicolumn{3}{|c|}{ case(12) } \\
\hline & $\operatorname{Det}(J)$ & $\operatorname{Tr}(\mathrm{J})$ & state & $\operatorname{Det}(J)$ & $\operatorname{Tr}(\mathrm{J})$ & state & $\operatorname{Det}(\mathrm{J})$ & $\operatorname{Tr}(\mathrm{J})$ & state \\
\hline$(0,0)$ & - & $\mathrm{N}$ & Saddle point & + & + & Instability point & - & $\mathrm{N}$ & Saddle point \\
\hline$(0,1)$ & + & + & Instability point & - & $\mathrm{N}$ & Saddle point & + & + & Instability point \\
\hline$(1,0)$ & - & $\mathrm{N}$ & Saddle point & - & $\mathrm{N}$ & Saddle point & + & - & ESS \\
\hline$(1,1)$ & + & - & ESS & + & - & ESS & - & $\mathrm{N}$ & Saddle point \\
\hline$\left(x_{0}^{\prime}, y_{0}^{\prime}\right)$ & \multicolumn{3}{|c|}{ meaningless } & & & & & & \\
\hline
\end{tabular}

There are several points about the results in the table above: 

uncertainty.

(2) Notes on the stability of equilibrium points. Taking case (1) as an example, according to the principle of evolutionary stability, the determinant $(\operatorname{Det}(\mathrm{J}))$ of point $(0,0)$ is greater than 0 , and the trace $(\operatorname{Tr}(J))$ is less than 0 , which means that $(0,0)$ is the evolutionary stable point of the system.

(3) The determinant of point $(0,1)$ and $(1,0)$ is less than 0 , and the trace is uncertain, which means that these two points are the saddle points of the system.

(4) At point $(1,1)$, both the determinant and trace are greater than 0 , which means that $(1,1)$ is the unstable point of the system.

(5) In particular, there is a fifth stable point $\left(x_{0}, y_{0}\right)$ in case 6). The characteristic root 277 corresponding to point $\left(x_{0}, y_{0}\right)$ is a pure imaginary number. According to the relevant literature not have asymptotic stability. The evolution trajectory of the system is a closed orbit loop around the center point $\left(x_{0}, y_{0}\right)$ is the central point of system evolution. In addition, if the determinant of point $\left(x_{0}, y_{0}\right)$ is uncertain and trace is zero, then it is neither a saddle point nor an unstable point. weak constraints on enterprises $\left(D_{2}\right)$ and the government $\left(D_{3}\right)$, so both sides lack strong constraints. In the long-term evolution process, there is an opportunistic tendency on both players 
of the game, and they have the motivation to choose passive behaviors. Therefore, the evolution equilibrium point of system must have $P_{1}(0,0)$, and there are strategies (NA, NR) between government and enterprises. At this time, the state of carbon-reduction is most passive, as shown in case (1)(3)(4) of Table 7.

When $D_{1}-C_{2}-S<0, R_{1}-C_{1}-R_{2}+D_{2}>0$, we can get $D_{1}<C_{2}+S, R_{1}-C_{1}>$ $R_{2}-D_{2}$. From $R_{1}-C_{1}>R_{2}-D_{2}$, we can further know that $R_{1}-C_{1}+S>R_{2}-F-D_{2}$. Under this circumstance, residents' willingness has strong constraints on enterprises. So regardless of government's action or inaction, enterprises can gain more profits by choosing CR. From $D_{1}<$ $C_{2}+S$, it can be seen that the constraint of enterprises' willingness on the government is not strong enough, so government will choose NA when enterprises reduce emissions. At this time, the evolutionary stable strategy is (NA, CR), and the carbon-reduction reaches a suboptimal state, as shown in case (2) 8 of Table 7.

When $F-C_{2}+D_{3}>0, R_{1}-C_{1}-R_{2}+D_{2}<-(S+F)$, we can get $F-C_{2}>-D_{3}, R_{1}-$ $C_{1}+S<R_{2}-F-D_{2}$. From $R_{1}-C_{1}-R_{2}+D_{2}<0$, we can further know that $R_{1}-C_{1}<$ $R_{2}-D_{2}$. Under such circumstance, due to the constraint of residents' willingness on enterprises $\left(D_{2}\right)$ is not enough, so regardless of government's action or inaction, NR is the best choice for enterprises. According to $F-C_{2}>-D_{3}$, we can see the constraint of residents' willingness on the government $\left(D_{3}\right)$ is strong. So government will take active action after confirming the behavior of enterprises. At this time, the evolutionary stable strategy is (AC, NR), and the carbon-reduction also reaches the suboptimal state, as shown in case (9) (12) of Table 7.

When $D_{1}-C_{2}-S>0, R_{1}-C_{1}-R_{2}+D_{2}>-(S+F)$, we can get $D_{1}>C_{2}+S, R_{1}-$ $C_{1}+S>R_{2}-F-D_{2}$. At this time, constraints of enterprises' willingness on the government $\left(D_{1}\right)$ 
and constraints of residents' willingness on enterprises $\left(D_{2}\right)$ have reached a certain intensity. Under such circumstance, government's choice of AC is more favorable when enterprises reduce emissions, and the best choice for enterprises when government acts is CR, which shows that both government and enterprises have incentives to take active actions to promote ESER. Obviously, the strengthening of public willingness has effectively promoted the government and enterprises to take positive actions. There must be an evolutionary stable strategy (AC, CR), at which time carbon-reduction can reach an optimal state, as shown in case (4)(5)(10)(11) of Table 7.

In particular, after joining the two conditions of $F-C_{2}+D_{3}<0$ and $R_{1}-C_{1}-R_{2}+D_{2}<$ 0 , government and enterprises may have negative behavior patterns. Although there are constraints of public willingness, there will be opportunistic tendency between the government and enterprises. Therefore, after a long-term evolution, $P_{1}(0,0)$ will also be a stable point of system evolution, as shown in case (4) of Table 7.

When $F-C_{2}+D_{3}>0, D_{1}-C_{2}-S<0$ and $-(S+F)<R_{1}-C_{1}-R_{2}+D_{2}<0$, we can get $F-C_{2}>-D_{3}, D_{1}<C_{2}+S, R_{1}-C_{1}+S>R_{2}-F-D_{2}$ and $R_{1}-C_{1}<R_{2}-D_{2}$. In this case, both government and enterprises will constantly adjust their behavior according to the choice of the other party. Obviously, there is a periodic behavior between government and enterprises. Due to the varying intensity of public willingness $\left(D_{1} 、 D_{2} 、 D_{3}\right)$, the behavior patterns of both government and enterprises are chaotic, and it is difficult to reach a stable behavior strategy. At this time, the system has only one central point $\left(x_{0}{ }^{\prime}, y_{0}{ }^{\prime}\right)$, and there is no evolutionary stable strategy, as shown in case (7) of Table 7. The behavior probability of government and enterprises fluctuates around the central point.

\section{Scenario analysis}



section further analyzes how the initial willingness and related parameters affect the dynamic evolution of government and enterprise strategies. Based on the evolutionary game model of government and enterprises that joins public willingness, the initial parameter values are assigned (Shi et al., 2013; Shen et al., 2011). The corresponding parameter values are $C_{1}=60, C_{2}=$ 53, $R_{1}=120, R_{2}=100, S=33, F=40$. Since $D_{1} 、 D_{2}$ and $D_{3}$ will bring losses to government or enterprises, $D_{1}$ can also be regarded as a constraint of enterprise willingness on the government, $D_{2}$ and $D_{3}$ can be regarded as the constraints of residents' willingness on enterprises and government respectively. $D_{1} 、 D_{2}$ and $D_{3}$ are not assigned temporarily, they will be changed according to the actual situation in various cases. Based on the parameter assignment and the actual situation, the situation of $R_{1}-C_{1}+S<R_{2}-F-D_{2}$ will not occur, so this paper does not give a specific analysis of case (3)(6)(12).

\subsection{The cases of government-enterprise cannot achieve the optimal path spontaneously} situations in which the enterprise willingness has a weak constraint on the government $\left(D_{1}<C_{2}+\right.$ $S$ ), and the two parties cannot spontaneously move towards the optimal path of ESER. willingness on government is $D_{1}=63$, the constraint of residents' willingness on enterprises is $D_{2}=20$, the constraint of residents' willingness on government is $D_{3}=10$. The condition satisfies $F-C_{2}+D_{3}<0, D_{1}-C_{2}-S<0$ and $-(S+F)<R_{1}-C_{1}-R_{2}+D_{2}<0$, which 


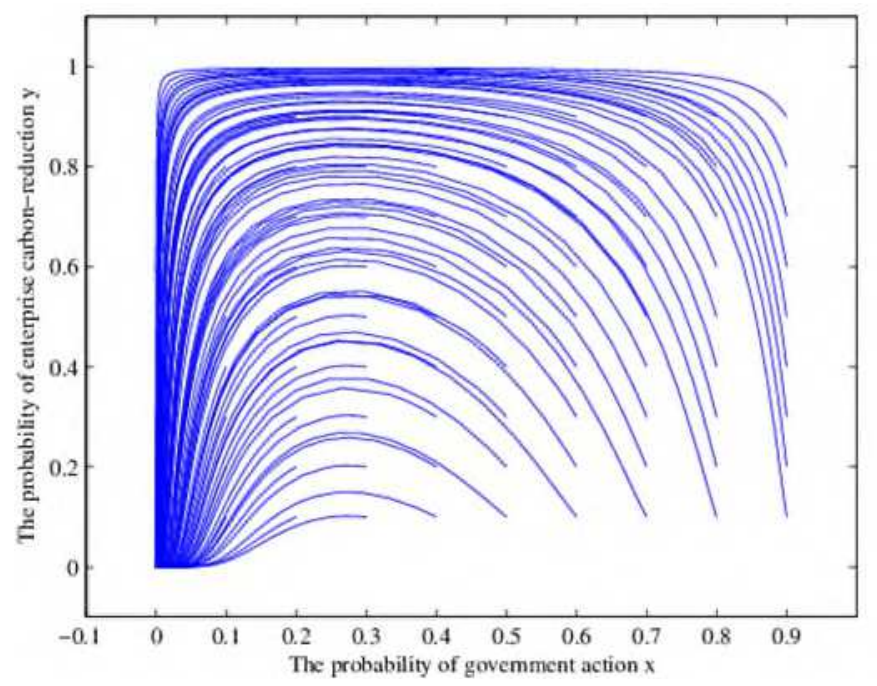

Fig.1 Dynamic evolution path for both strategies in scenario No.1

Fig. 1 depicts the dynamic evolution path of government and enterprise over time. Different

behavior probabilities. The level of initial behavior probability can measure the strength of the

initial willingness of both sides. It can be seen that $(0,0)$ is the evolutionary stable point of system.

No matter what the initial willingness of both parties is, they will eventually converge to the

government are relatively weak, NA is the best choice for government whether enterprises reduce emissions or not. The strategy of enterprises will eventually tend to NR with the determination of government behavior.

Fig. 2 and Fig. 3 respectively depict the dynamic evolution path of government and enterprise behavior strategies over time in case (1). The vertical axis of the two graphs respectively represents the probability of $\mathrm{AC}$ and probability of CR. Horizontal axis represents time t. The data in this study are simulated data, so the unit of $t$ is not specifically set (such as year, month, etc.), but refers to a general unit of time, which is used to examine the convergence speed of government 
372

373

374

and enterprise behavior. In order to better compare and analyze the impact of different initial willingness on the evolution of system, this paper sets the initial willingness of enterprises to reduce emissions and the initial willingness of governments to act as low, medium and high levels, namely $(0.2,0.5,0.8)$. As shown in Fig. 2, The rays from the three endpoints of $x=0.8, x=$ $0.5, x=0.2$ indicate the evolution path of government behavioral strategy when government's initial willingness is high, medium, and low. There are three rays of red, green and blue from each endpoint. They respectively show the evolution path of government behavioral strategy under the fixed government's initial willingness and different enterprises' initial willingness $(\mathrm{y}=0.2, \mathrm{y}=$ $0.5, y=0.8)$. Fig. 3 similarly shows the evolution path of enterprise strategies under different initial government willingness $(x=0.2, x=0.5, x=0.8)$.

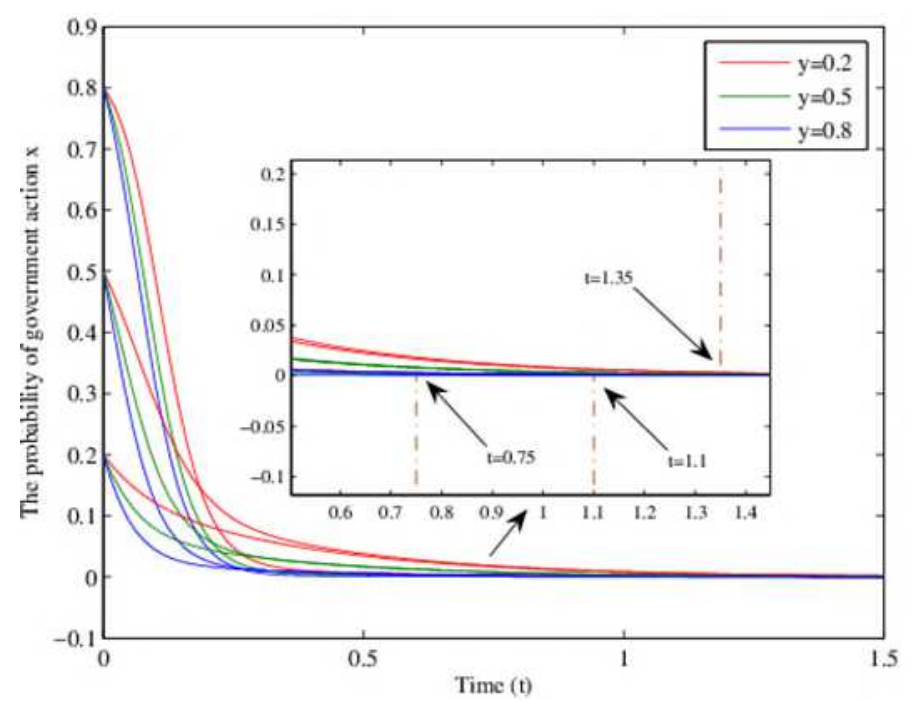

Fig.2 Dynamic evolutionary paths of government strategy in scenario No.1

As shown in Fig. 2, government's behavior probability $x$ will eventually converge to zero. Beyond that, the greater the enterprises' initial willingness to reduce emissions, the faster the government's behavioral probability $x$ converges toward zero. Reflected in the graph, the time for the blue, green, and red rays to converge to 0 is $0.75,1.1$, and 1.35 , respectively. Since the cost of government action $\left(C_{2}+S\right)$ is large when enterprises reduce emissions, if government 
observes that enterprises have a strong willingness to reduce emissions during the evolutionary game, it will speed up the adjustment of its own behavior. More specifically, when the initial willingness of enterprises is low (e.g., $\mathrm{y}=0.2$ ), the convergence rate of $x$ will accelerate as government's initial willingness increases. Shown graphically, the ray from $x=0.8$ is the fastest of three red rays. The situation is similar for $y=0.5$. Due to the weak constraint of residents' willingness on the government $\left(D_{3}\right)$, government will urgently tend to the favorable strategy of NA when the willingness of enterprises is low. If the initial willingness of enterprises is high $(y=$ 0.8), government will not adjust its own behavior quickly because of the relatively strong constraint of enterprise willingness $\left(D_{1}\right)$. The convergence rate of government's action probability $x$ will only accelerate with the decrease of its initial willingness.

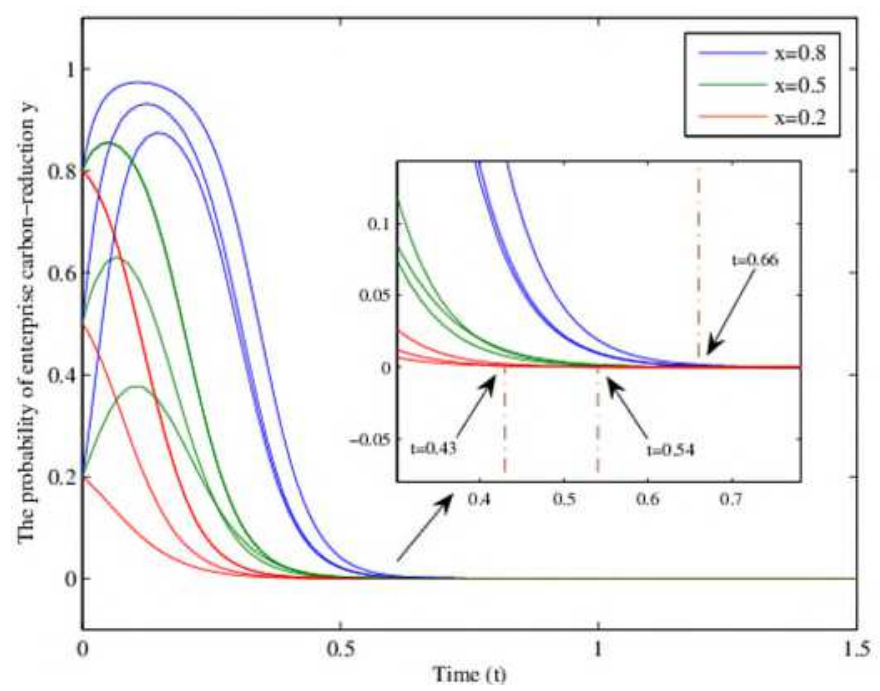

Fig.3 Dynamic evolutionary paths of enterprise strategy in scenario No.1

As shown in Fig. 3, enterprises' behavior probability $y$ will eventually converge to zero. Beyond that, the convergence rate of $y$ will be accelerated with the reduction of enterprise's initial willingness. Reflected graphically, when government's initial willingness is certain (e.g., $x$ $=0.2$ ), the ray starting from $y=0.2$ converges the fastest among the three red rays. On the other hand, the convergence rate of $y$ will slow down with enhancement of government's initial 
willingness, and will also rise briefly when the government's initial willingness is strong. Reflected in the graph, the time for red, green and blue rays to converge to 0 is $0.43,0.54$ and 0.66 respectively. Moreover, the blue and green rays will rise briefly at $t \in[0,0.25]$ and then fall. The main reason is that the profit of enterprises is greatly influenced by government behavior. When government's initial willingness is strong, enterprises will increase the probability of emission reduction, and then decrease with government's inaction.

Enterprises actively reduce emissions, and government does not act. Suppose $D_{1}=63$, $D_{2}=50, D_{3}=10$. The condition satisfies $F-C_{2}+D_{3}<0, D_{1}-C_{2}-S<0$ and $R_{1}-C_{1}-$ $R_{2}+D_{2}>0$, which is in line with case (2). At this time, (NA, CR) is the evolutionary stable strategy of the system. In this case, the constraints of enterprise willingness on government $\left(D_{1}\right)$ and residents' willingness on government $\left(D_{3}\right)$ are relatively weak. Therefore, no matter what the initial willingness of enterprises, government's behavioral strategy will not fluctuate greatly. Government will only choose NA ultimately. The residents' willingness has a strong constraint on enterprises $\left(D_{2}\right)$, and if enterprises do not reduce emissions while government is acting, they will also have to bear government's fine. Therefore, enterprises will step up their emission reduction efforts with strengthening of government's initial willingness.

Suppose $D_{1}=63, D_{2}=50, D_{3}=20$. The condition satisfies $F-C_{2}+D_{3}>0, D_{1}-C_{2}-$ $S<0$ and $R_{1}-C_{1}-R_{2}+D_{2}>0$, which is in line with case (8). Case (8) is similar to case (2). The evolutionary stable point of the system is $(0,1)$, and the evolutionary stable strategy is (NA, CR). In addition, the behavior patterns of two parties are similar to Case (8). In terms of parameter conditions, case (8) enhances the constraint of residents' willingness on the government $\left(D_{3}\right)$ compared with case (2). However, government can avoid losses caused by resident's blame 
because enterprises must choose ER. Therefore, in the long-term evolution, government will also choose NA (Due to space limitations, the evolution graph and corresponding analysis of the above two cases are omitted).

Government and enterprises have no established behavioral strategy. Suppose $D_{1}=43$, $D_{2}=20, D_{3}=20$. The condition satisfies $F-C_{2}+D_{3}>0, D_{1}-C_{2}-S<0$ and $-(S+$ $F)<R_{1}-C_{1}-R_{2}+D_{2}<0$, which is in line with case (7).

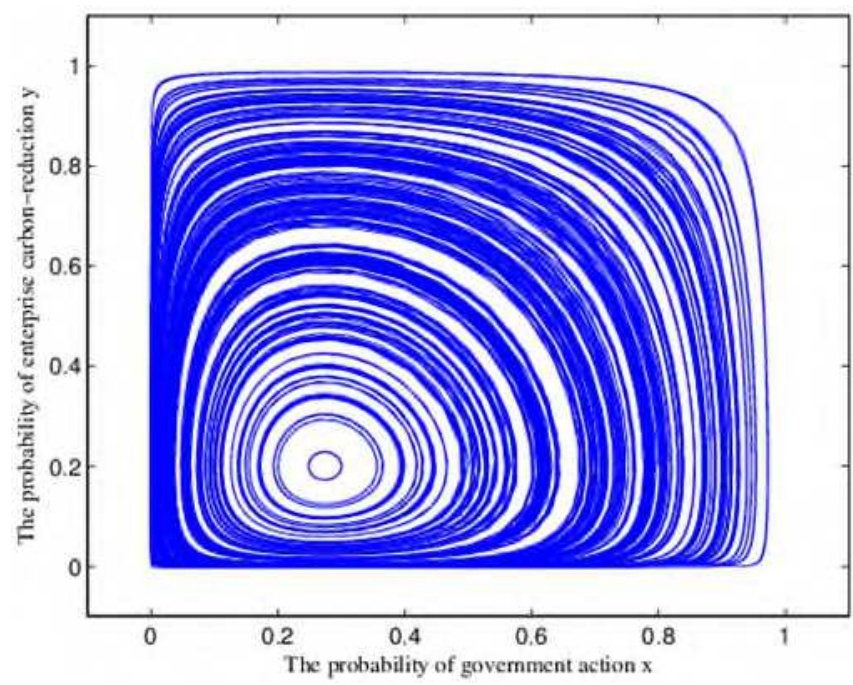

Fig.4 Dynamic evolution path for both strategies in scenario No.7

Case (7) is special. There is only one central point in system evolution, and there is no evolutionary stable strategy. Fig.4 depicts the dynamic evolution path of government and enterprises over time under different initial willingness. As shown in Fig. 4, the system evolution process is a closed-orbit line loop that periodically moves around the center point $\left(x_{0}{ }^{\prime}, y_{0}{ }^{\prime}\right)$, and there is no limit cycle. The game process of two parties shows a periodic behavior pattern.

Calculated according to the system parameters: $x_{0}{ }^{\prime}=\frac{-R_{1}+C_{1}+R_{2}-D_{2}}{S+F}=0.274, y_{0}{ }^{\prime}=\frac{F+D_{3}-C_{2}}{S+F+D_{3}-D_{1}}=0.2$, so the center point is $(0.274,0.2)$.

\subsection{The cases of achieving the optimal path spontaneously}

In the following cases, the willingness of enterprises has a strong constraint on the 
government $\left(D_{1}>C_{2}+S\right)$. Both government and enterprises can spontaneously move towards the optimal path of ESER. The enhancement of residents' willingness to restrain government and enterprises $\left(D_{2} 、 D_{3}\right)$ can further improve the situation of carbon-reduction.

Government and enterprises have two optimal strategy combinations. Suppose $D_{1}=$ 93, $D_{2}=5, D_{3}=10$. The condition satisfies $F-C_{2}+D_{3}<0, D_{1}-C_{2}-S>0$ and $-(S+$ $F)<R_{1}-C_{1}-R_{2}+D_{2}<0$, which is in line with case (4).

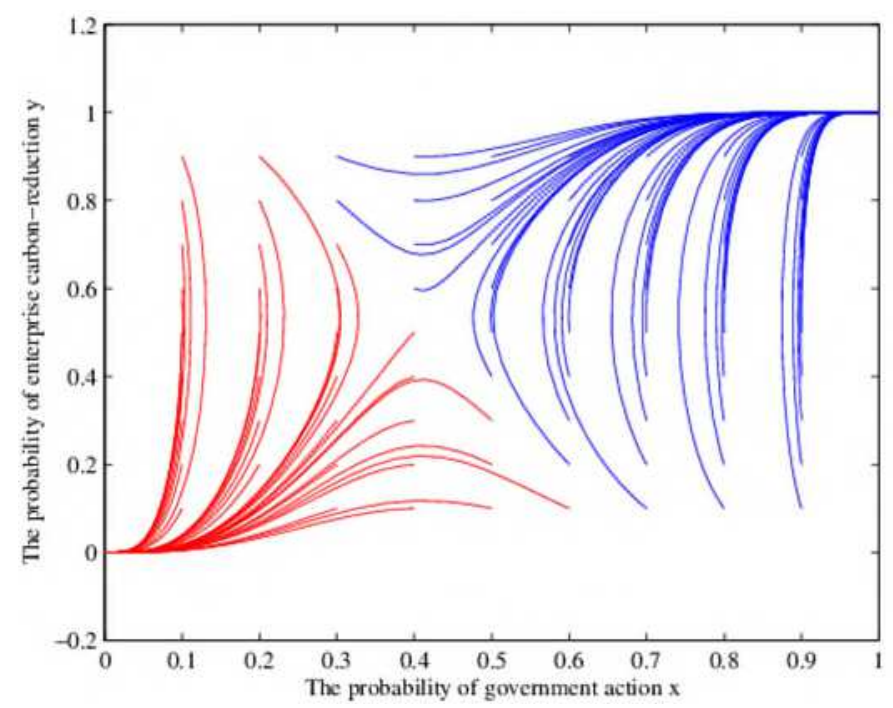

Fig.5 Dynamic evolution path for both strategies in scenario No.4

Fig. 5 depicts the dynamic evolution path of government and enterprises over time. The red line indicates that the behavior probability of government and enterprises eventually approaches $(0$, $0)$. The blue line indicates that the behavior probability of two players eventually converges to (1, 1). In this case, government will take active actions when enterprises reduce emissions, and enterprises will choose emission reduction when government acts. Conversely, vice versa. So there are two evolutionary stable strategies in the system, namely (AC, CR) and (NA, NR). This situation can partly tend to the optimal state of carbon-reduction. So the following article will examine whether we can increase situations of (AC, CR) through the change of parameters, so as to optimize the path of ESER. 


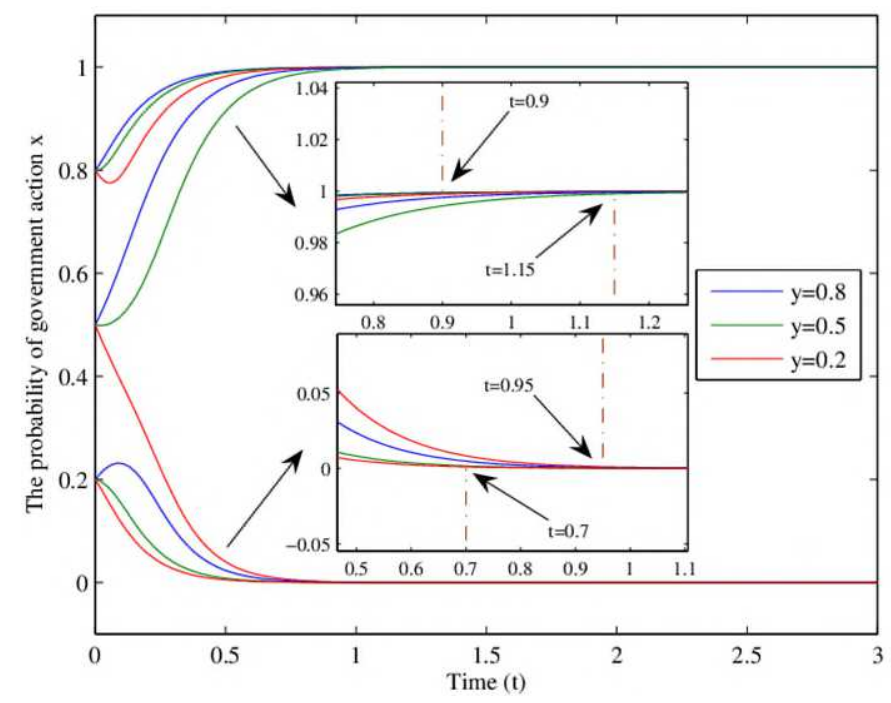

Fig.6 Dynamic evolutionary paths of government strategy in scenario No.4

Fig. 6 and Fig. 7 respectively depict the dynamic evolution path of government and enterprise behavior strategies over time. As shown in Fig. 6, it can be found that when government's initial willingness is high $(x=0.8)$ or low $(x=0.2)$, the enterprises' initial willingness has no significant impact on government's behavior. When government's initial willingness is moderate $(x=0.5)$, government behavior will be influenced by the initial willingness of enterprises. Only when the initial willingness of enterprises is low $(y=0.2)$, government's action probability $x$ will tend to 0 , otherwise it will tend to 1 . Shown graphically, all three rays starting from $x=0.8$ converge to 1 and the convergence speed is approximately the same. All three rays starting from $x$ $=0.2$ converge to 0 and the speed is about the same. Starting from $x=0.5$, the blue and green ray converge to 1 , and the red ray converge to 0 . In this case, the constraint of residents' willingness on the government $\left(D_{3}\right)$ are relatively weak. Although enterprise willingness $\left(D_{1}\right)$ has a strong constraint on the government, government can fully bear the losses caused by irrational strategies. Due to the existence of behavioral inertia, when the initial willingness of government is relatively certain $(x=0.2$ or $x=0.8)$, it will not change its own strategy. When government's initial willingness is uncertain $(x=0.5)$, it will determine its optimal strategy based on the behavior of 
enterprises.

On the other hand, government's initial willingness has a positive correlation with the convergence rate of its behavior probability. As shown in the graph, when enterprises' initial willingness is determined (such as $y=0.5$ ), the convergence time of two green rays from $x=$ 0.8 and $x=0.5$ to 1 is 0.9 and 1.15 respectively. Obviously, the improvement of government's initial willingness accelerates the convergence of $x$ to 1 . Given $y=0.2$, the convergence time of two red rays from $x=0.5$ and $x=0.2$ to 0 is 0.95 and 0.7 respectively. It shows that the decrease of government's initial willingness accelerates the convergence of $x$ to 0 .

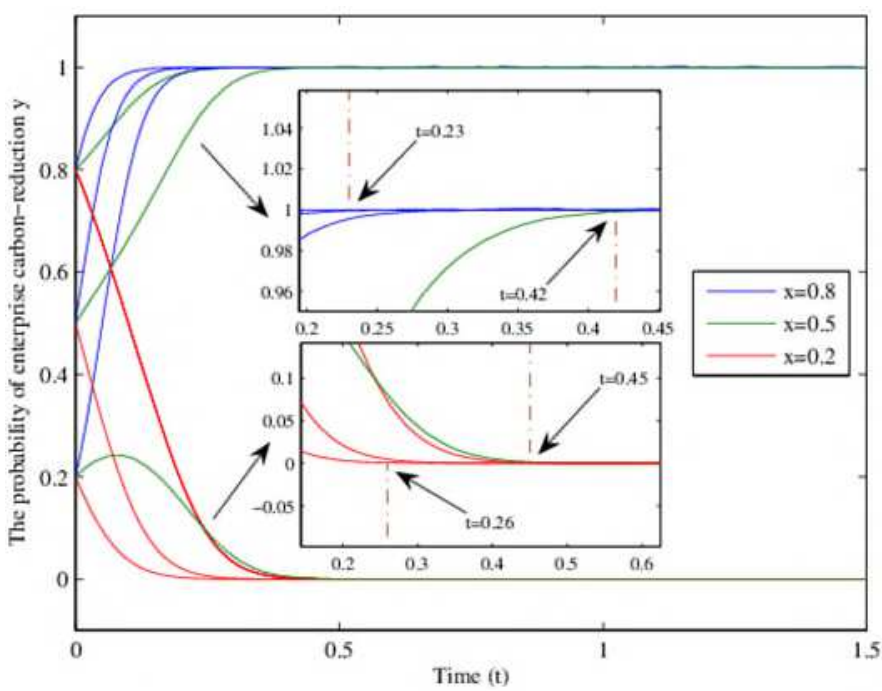

Fig.7 Dynamic evolutionary paths of enterprise strategy in scenario No.4

As shown in Fig.7, we can know that government's initial willingness has a great impact on the behavior of enterprises. When the initial willingness of government is high $(x=0.8)$ or low $(x$ $=0.2$ ), the behavior probability of enterprises will eventually tend to 1 or 0 . When government's initial willingness is moderate $(x=0.5)$, enterprises will make a choice based on their initial willingness. Only when enterprises' initial willingness is low $(y=0.2), y$ will tend to 0 , otherwise it will converge to 1 . Graphically, all three blue rays converge to 1 , and all three red rays converge to 0 . Only one green ray starting from $y=0.2$ tend to 0 , while the other two green rays 
converge to 1 . Due to the weak constraint of residents' willingness $\left(D_{2}\right)$ on enterprises, the best choice for enterprises is NR when government does not act. However, when government has a strong willingness of action, it is difficult for enterprises to bear the double losses caused by government's fine $(F)$ and residents' willingness $\left(D_{2}\right)$. So enterprises will inevitably choose CR. When government's initial willingness is moderate, enterprises will determine the ultimate strategy according to their initial willingness.

On the other hand, government's initial willingness will also affect the convergence rate of enterprise behavior probability. Reflected in the graph, the convergence time of blue ray from $y=0.5$ to 1 is 0.23 , while that of green ray from $y=0.5$ is 0.42 . It shows that the enhancement of government's initial willingness will accelerate the convergence rate of $y$ to 1 . The convergence time of red ray from $y=0.2$ to 0 is 0.26 , while that of green ray from $y=0.2$ is 0.45 . It shows that the decrease of government's initial willingness will accelerate the convergence rate of $y$ to 0 .

Suppose $D_{1}=93, D_{2}=10, D_{3}=12$. The parameter conditions are consistent with case (4).

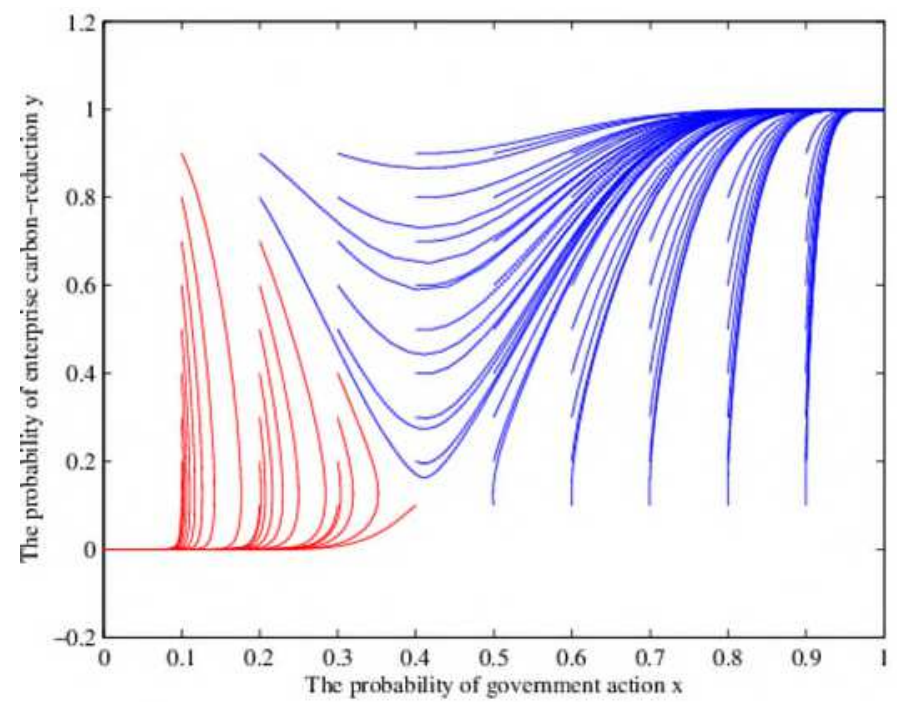

Fig.8 Dynamic evolutionary paths for both strategies in scenario No.4 $\left(D_{3}=12\right)$

Fig. 9 depicts the dynamic evolution path of government and enterprises over time when $D_{3}$ is increased to 12 and other conditions are unchanged. Comparing Fig. 8 with Fig. 5, we can find 

increased. The state of carbon-reduction has been optimized to some extent.

Suppose $D_{1}=93, D_{2}=20, D_{3}=5$. The parameter conditions also meet the case (4).

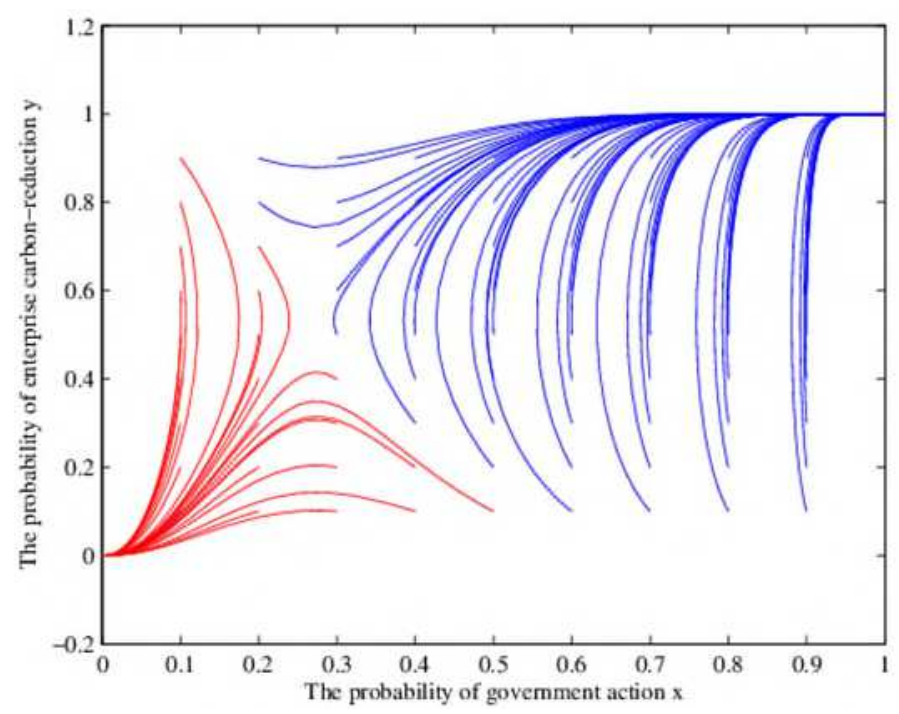

Fig.9 Dynamic evolutionary paths for both strategies in scenario No.4 $\left(D_{2}=20\right)$

Fig. 9 depicts the dynamic evolution path of government and enterprises over time when $D_{2}$ is increased to 20 and other conditions are unchanged. Comparing Fig. 9 with Fig. 5, it can be found that with the enhancement of residents' constraint on enterprises, situations of (AC, CR) have increased. The state of carbon-reduction has been optimized to some extent.

If $D_{1}, D_{2}$, and $D_{3}$ increase at the same time, they are $D_{1}=103, D_{2}=20$, and $D_{3}=12$. The parameter conditions are also consistent with case (4). 


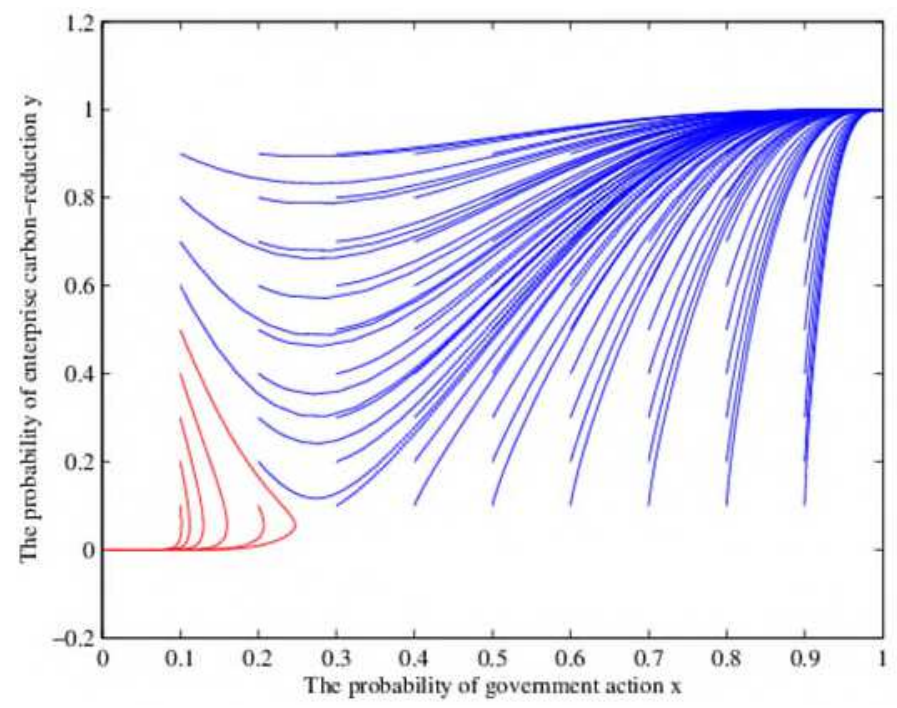

Fig.10 Dynamic evolutionary paths for both strategies in scenario No.4 $\left(D_{1}=103, D_{2}=20, D_{3}=12\right)$

Fig. 10 depicts the dynamic evolution path of government and enterprises over time when $D_{1}$, $D_{2}$, and $D_{3}$ are improved together. Compared to Fig. 8 and 9 , situations of (AC, CR) have increased more in Fig. 10. The state of carbon-reduction has been greatly optimized. It shows that a joint strengthen of resident and enterprise willingness is more conducive to the achievement of the optimal path.

According to the above analysis, the increase of $D_{1}, D_{2}$, and $D_{3}$ is conducive to the optimization of carbon-reduction status. However, the continuous improvement of $D_{2}$ and $D_{3}$ will change the case (4) into other cases. So we will try to keep $D_{2}$ and $D_{3}$ unchanged $\left(D_{2}=10\right.$, $D_{3}=5$ ), continuously strengthen the willingness of enterprises $\left(D_{1}\right)$. Then observe whether the behavior of government and enterprises will change significantly. Through a large number of parameter simulation and simulation, it is found that with the continuous improvement of enterprise willingness, there are fewer and fewer situations of (NA, NR). Until $D_{1}$ is greater than or equal to 412, the situation of (NA, NR) disappears. 


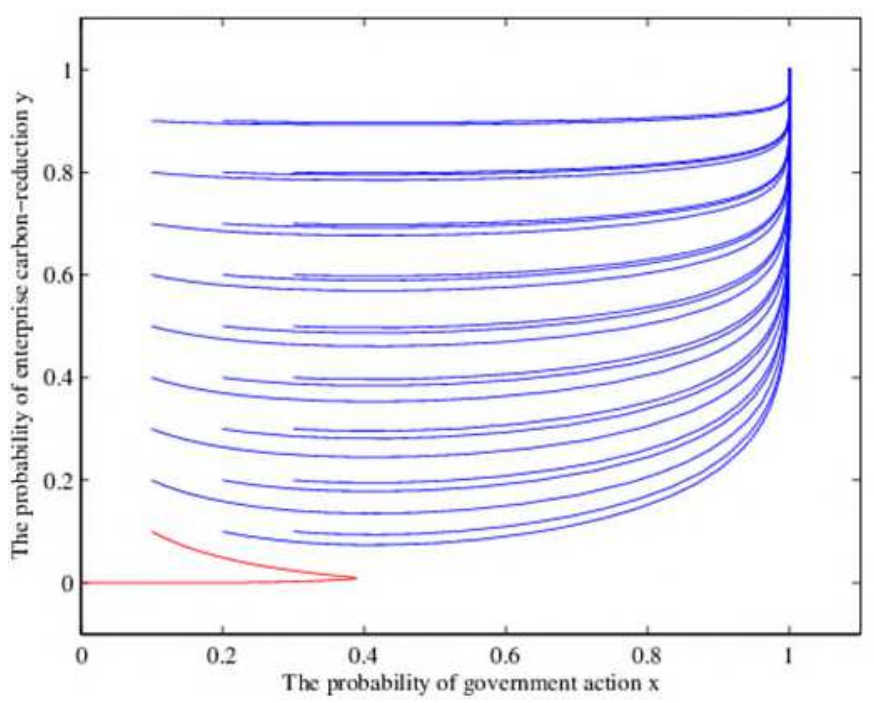

Fig.11 Dynamic evolutionary paths for both strategies in scenario No.4 $\left(D_{1}=411\right)$

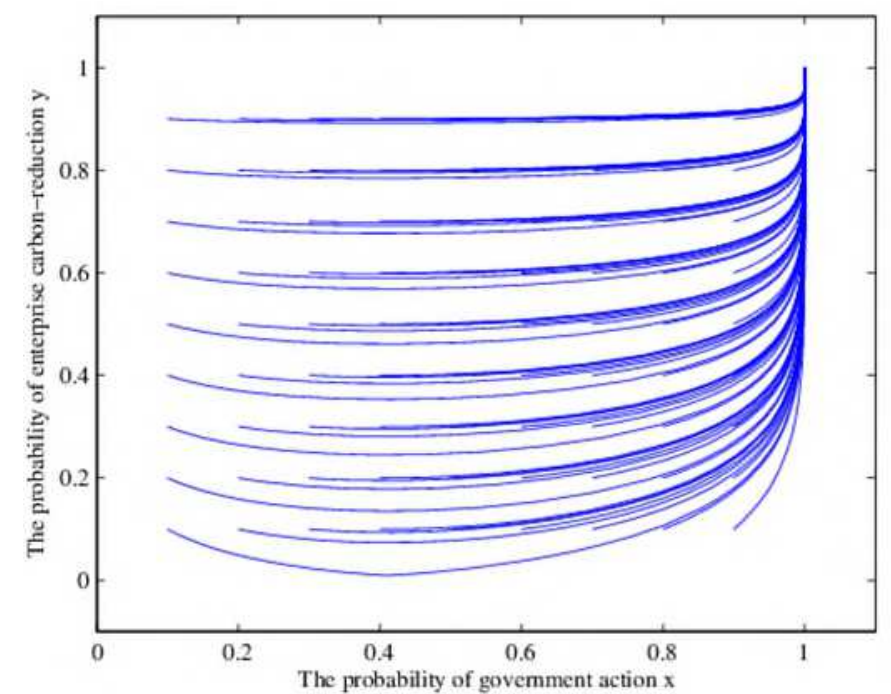

Fig.12 Dynamic evolutionary paths for both strategies in scenario No.4 $\left(D_{1}=412\right)$

As shown in Fig. 11 and Fig. 12, when $D_{1}$ is 411, the situation will converge to (NA, NR)

544 only when the initial behavior probability of two players is $(0.1,0.1)$. When $D_{1}$ is increased to 412, government and enterprises will converge to (AC, CR) under any initial behavior probability. Under this circumstances, the result of two equilibrium strategies does not match the case(4). The main reason is that the willingness of enterprises is too strong. If government does not give enterprises subsidies for reducing emissions, government will be unable to bear the huge losses caused by enterprises' blame. At the same time, government can fully bear the loss of action 
551 weighing.

Both government and enterprises take active action. Suppose $D_{1}=93, D_{2}=50, D_{3}=10$.

The condition satisfies $F-C_{2}+D_{3}<0, D_{1}-C_{2}-S>0$ and $R_{1}-C_{1}-R_{2}+D_{2}>0$, which is in line with case (5).

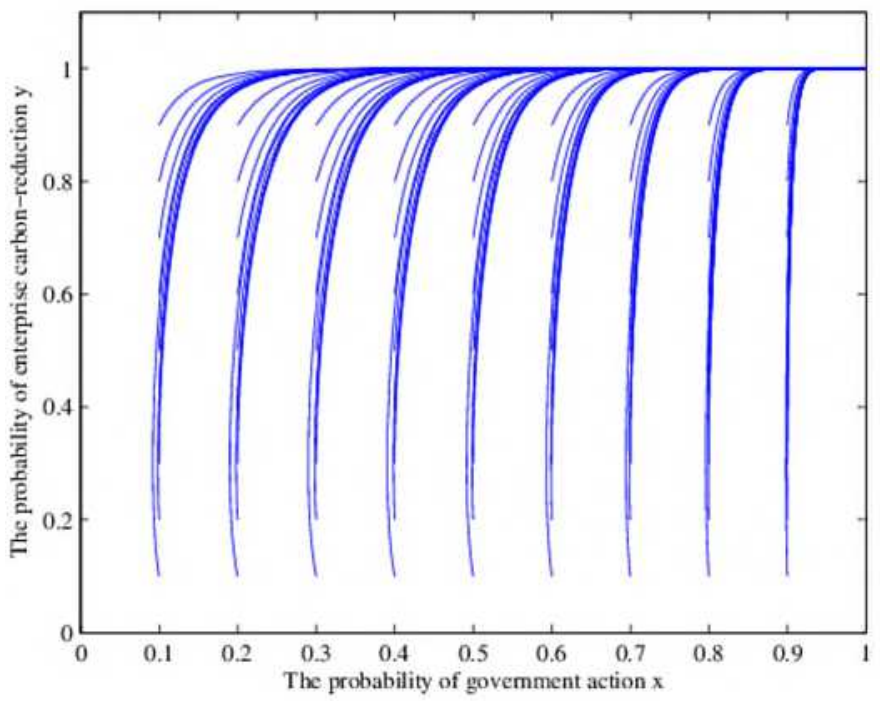

Fig.13 Dynamic evolutionary paths for both strategies in scenario No.5

Fig. 13 depicts the dynamic evolution path of government and enterprises over time. It can be seen that $(1,1)$ is the evolutionary stable point of system. No matter what the initial willingness of both parties is, they will eventually converge to the strategy (AC, CR).

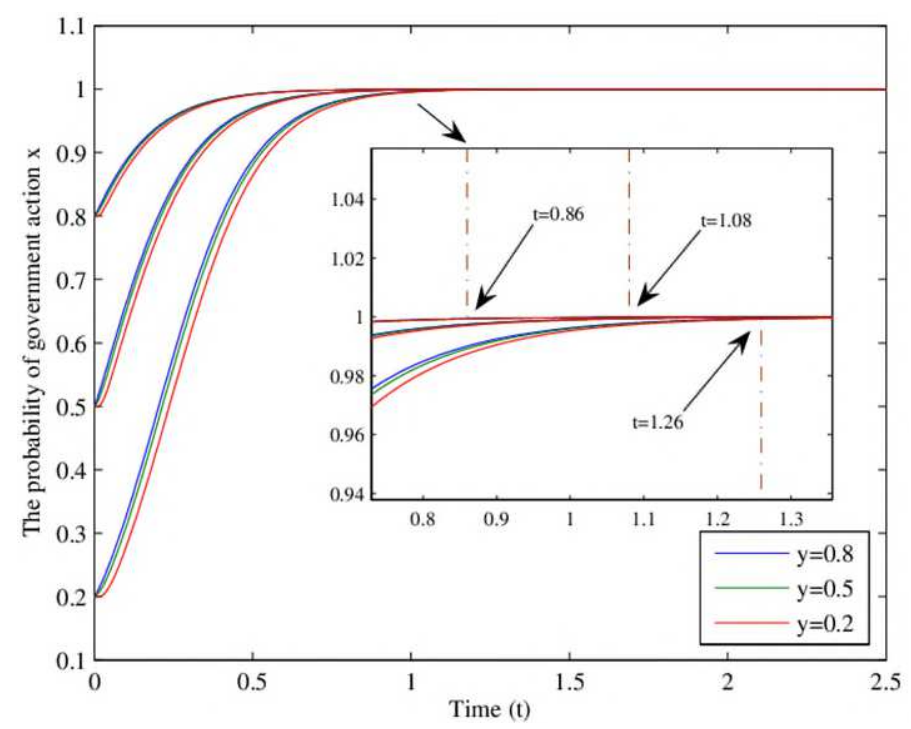

31 
Fig. 14 and Fig. 15 respectively depict the dynamic evolution path of government and government's initial willingness. Reflected in the graph, when enterprises' initial willingness is given (e.g., $y=0.2$ ), the convergence time of three red rays from $x=0.8, x=0.5$ and $x=0.2$ is

571 government is unwilling to bear the loss of credibility and coordination costs brought by

572 enterprises' harsh criticism. At the same time, the loss of government action will not be too much

willingness is, government's behavioral strategy will not fluctuate greatly.

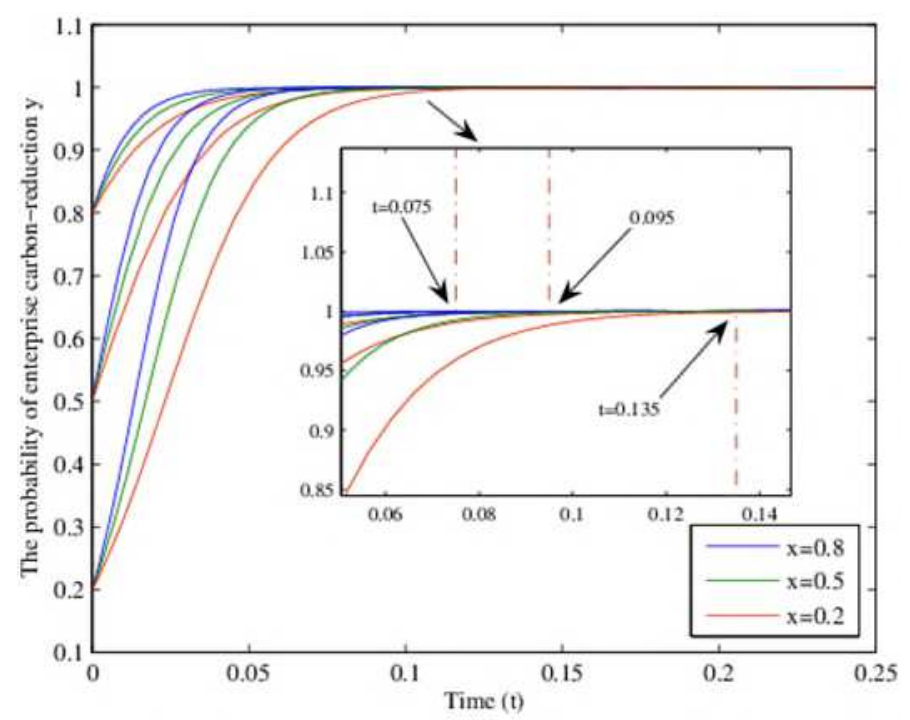



that, the convergence rate of $y$ is positively related to enterprises' initial willingness. Expressed graphically, when government's initial willingness is given (e.g., $x=0.2$ ), the ray starting from $y$ $=0.8$ converges at the fastest rate among the three red rays. On the other hand, enhancement of government's initial willingness is conducive to increasing the convergence rate of $y$. Shown graphically, the time for blue, green and red rays to converge to 1 is $0.075,0.095$ and 0.135 respectively. In this case, residents' willingness has a strong constraint on enterprises. And if enterprises do not reduce emissions while government acts, they will also bear the fine from government. Therefore, once enterprises observe that government has a strong willingness to act, they will enhance their emission reduction efforts to avoid being punished by government. government acts or does not act, the best choice for enterprises is CR. At the same time, due to the weak constraint of residents' willingness on the government $\left(D_{3}\right)$ and the strong constraint of enterprise willingness $\left(D_{1}\right)$, government behavior is mainly affected by enterprises. Government will ultimately choose AC according to the behavior of enterprises. So there is a lag in the government's behavioral strategy.

Suppose $D_{1}=93, D_{2}=20, D_{3}=20$. The condition satisfies $F-C_{2}+D_{3}>0, D_{1}-C_{2}-$

$$
S>0 \text { and }-(S+F)<R_{1}-C_{1}-R_{2}+D_{2}<0 \text {, which is in line with case (10). }
$$




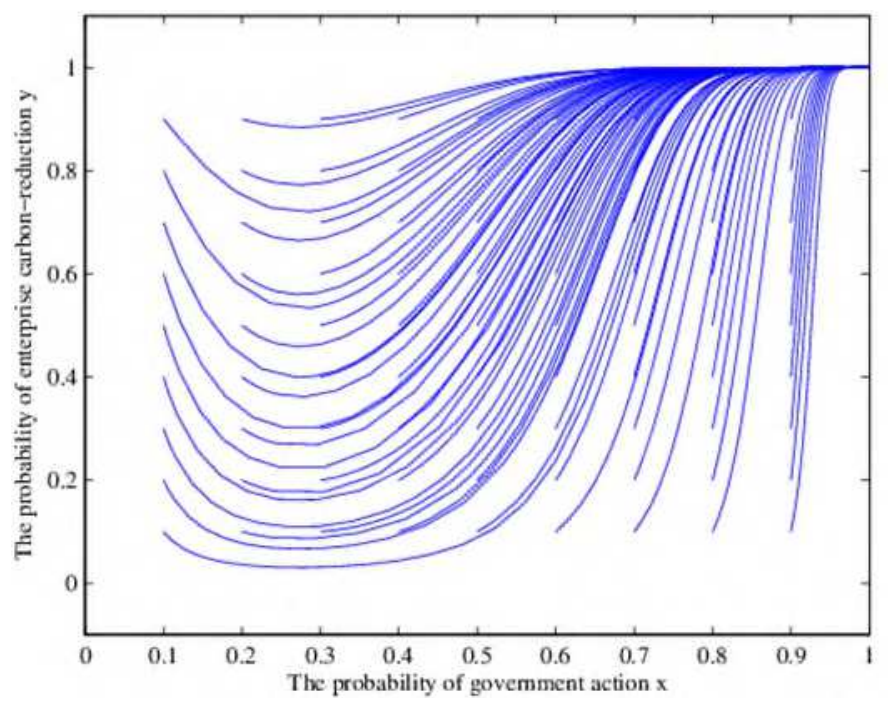

Fig.16 Dynamic evolutionary paths for both strategies in scenario No.10

Fig. 16 depicts the dynamic evolution path of government and enterprises over time. It can be government $\left(D_{1}\right)$ are relatively strong. So whether enterprises reduce emissions or not, government's best choice is AC. At the same time, due to the weak constraint of residents' lag in enterprises behavioral strategy. 


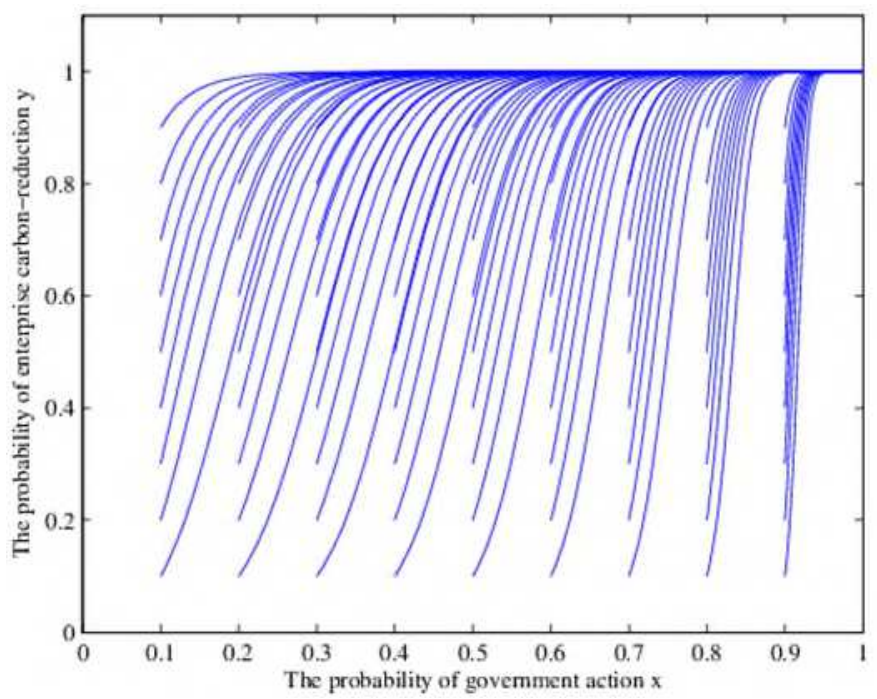

609

610

611

612

613

614

Fig.17 Dynamic evolutionary paths for both strategies in scenario No.11

Fig. 17 depicts the dynamic evolution path of government and enterprises over time. It can be seen that $(\mathrm{AC}, \mathrm{CR})$ is the evolutionary stable strategy of system. In this case, government will firmly choose AC, because the constraints of residents' willingness on government $\left(D_{3}\right)$ and enterprise willingness on government $\left(D_{1}\right)$ are relatively strong. At the same time, due to the strong constraint of residents' willingness on enterprises $\left(D_{2}\right)$, the best choice for enterprises is ER.

Under the incentive of maximizing their own interests, both government and enterprises will take active actions to promote carbon-reduction. Compared with case (5) and case (10), case (11) avoids possible losses caused by the lag strategy of government or enterprises. The path of ESER is further optimized.

\section{Policy recommendations}

Government and enterprises could not reach the optimal path of ESER through spontaneous behavior for lack of necessary constraints. In the formulation and implementation of carbon-reduction policies, the impact of public willingness must be fully considered. A series of measures must be taken to strengthen the constraints of public willingness on the government and enterprises. 

be realized, the enhancement of this constraint is of paramount importance. The shift from section business people and the establishment of government-enterprise information exchange platforms are helpful in conveying the wishes of enterprises. Enterprises should pay attention to the maintenance of their own rights and interests in ESER. They can exert pressure on the government through enterprise groups or industry associations, which can force government to take action to improve their consistency in the work of carbon-reduction. For example, the increasing willingness of enterprises in case (4) can eliminate the passive behavior of government, and achieve the optimal state of carbon-reduction. strengthens constraints on enterprises and government, and then makes case (4) change to case (5) and case (10) respectively. The simultaneous enhancement of both in situation (11) can eliminate the lag of government and enterprise strategies, and further improve the state of carbon-reduction. Government should strive to broaden the channels of residents' willingness feedback. Such means as letters and visits, social software, news media and so on can help residents express their wishes or suggestions on ESER. Then the constraint of residents' willingness on government will be strengthened. More attention should be payed to the collection

644 and release of enterprise environmental information. The community should be guided to 645 supervise enterprises' carbon-reduction. Then the constraint of residents' willingness on enterprises will be strengthened. 
to reach the optimal path. The above research shows that the higher initial willingness means the earlier optimal state of carbon-reduction. The optimal path of ESER could be promoted in specific circumstances. Relatively speaking, the improvement of government initial willingness is more important. The implementation of relevant national policies or regulations can provide government with codes of conduct, and enhance the initial willingness of government action. Introducing environmental governance satisfaction into the performance appraisal indicators can fundamentally increase the enthusiasm of relevant departments' action. Tax relief can reduce the economic pressure on enterprises to reduce emissions. Multiple measures such as unified carbon market and perfect carbon pricing mechanism could encourage enterprises to improve their initial willingness of carbon-reduction.

\section{Conclusions and prospects}

In this paper, an evolutionary game model of carbon-reduction between government and enterprises is built with public willingness constraints. The evolutionary stable strategies of both players of the game are analyzed. With the aid of numerical simulation, the behavior strategies of both players in different situations are discussed. The results show that in absence of public willingness constraints, there are three evolutionary stable strategies in the game between government and enterprises, which are (NA, NR), (NA, CR) and (AC, NR). Without necessary constraints, both government and enterprises cannot achieve the optimal state of carbon-reduction through spontaneous behavior.

Under the constraint of public willingness, there are four evolutionary stable strategies and a situation of constant fluctuation around the central point in the evolutionary game. Both government and enterprises can spontaneously tend to the optimal state (AC, CR). The constraint 
670

671

672

673

674

675

of enterprise willingness on the government $\left(D_{1}\right)$ plays a vital role in carbon-reduction. Only if this constraint is strong enough, government will choose AC, so as not to dampen the enthusiasm of enterprises to reduce emissions. Under the premise of strong enterprise willingness, the enhancement of residents' willingness can further restrict behavior of government and enterprises.

These can eliminate the possibility of passive strategies adopted by both government and enterprises, and reduce the hysteresis of strategies. And then further optimize the path of ESER.

The initial willingness of government and enterprises will have a certain impact on the path of ESER. The initial willingness will enhance their behavior. The stronger initial willingness, the faster convergence speed of behavior probability. Beyond that, the initial willingness of government and enterprises will have a certain impact on each other's behavior. This impact is mainly reflected in the convergence rate of behavior probability. On the other hand, in the specific situation (case (4)), the initial willingness of both government and enterprises will determine the other's ultimate behavioral strategy.

This paper studies the impact of public willingness on government and enterprises carbon-reduction strategies. The data in the scenario analysis are all drawn up. If real statistical data can be obtained, the analysis results will be closer to the real situation. In addition, the implementation of the carbon trading system will have a great impact on the results of this carbon-reduction game. Therefore, future research will consider how carbon quotas, carbon prices, and other factors affect government and enterprises behavior after obtaining statistical data. The optimal path of ESER will be further explored in the future.

Acknowledgements We are grateful to the valuable comments and suggestions of the anonymous referees. 
692

693

694

695

696

697

698

699

700

701

702

703

704

705

706

707

708

709

710

711

712

713

Availability of data and materials The datasets used and/or analyzed during the current study are available from the corresponding author on reasonable request.

Author contribution Guochang Fang: Conceptualization, Methodology, Software, Formal analysis, Writing - Review \& Editing, Funding acquisition

Yu He: Investigation, Data curation, Validation, Visualization, Writing - Original Draft

Lixin Tian: Resources, Formal analysis, Supervision, Funding acquisition

Funding The research is supported by the National Natural Science Foundation of China (Nos. 71774077, 71690242), Jiangsu “Qing Lan” Project (No. JS20190401), Jiangsu “Six Talent Peaks” High level Talent Project (No. JNHB-026), Major Research plan of the National Natural Science Foundation of China (No. 91546118), Jiangsu Social Science Foundation Project (No. 18EYB020).

\section{Declarations}

Ethics approval Not applicable

Consent to participate Not applicable

Consent to publication All authors reviewed and approved the manuscript for publication.

Competing interests The authors declare that they have no known competing financial interests or personal relationships that could have appeared to influence the work reported in this paper.

\section{References}

Chen W, Hu Z H (2018) Using evolutionary game theory to study governments and manufacturers' behavioral strategies under various carbon taxes and subsidies. J Clean Prod 201: 123-141.

Fan R, Dong L (2018) The dynamic analysis and simulation of government subsidy strategies in low-carbon diffusion considering the behavior of heterogeneous agents. Energ Policy 117: 
Fan R, Dong L, Yang W, Sun J (2017) Study on the optimal supervision strategy of government low-carbon subsidy and the corresponding efficiency and stability in the small-world network context. J Clean Prod 168:536-550.

Friedman D (1991) Evolutionary Game in Economics. Econometrica 59(3):637-666.

Friedman D (1998) On economic applications of evolutionary game theory. J Evol Econ 8(1):15-43.

Hårsman B, Quigley J M (2010) Political and public acceptability of congestion pricing: Ideology and self - interest. J Policy Anal Manag 29(4): 854-874.

Jiao J, Xu, Y, Li J, Yang R (2021) The evolution of a collaboration network and its impact on innovation performance under the background of government-funded support: an empirical study in the Chinese wind power sector. Environ Sci Pollut R 28:915-935.

Kreps D M (1990) Game Theory and Economic Modeling. J Econ Educ_23(2): 99-109.

Li J, Jiao J, Tang Y (2019) An evolutionary analysis on the effect of government policies on electric vehicle diffusion in complex network. Energ policy 129: 1-12.

Li L, Zhu B, Jiang M, Cai X, Antonio K, Geon-Cheo S (2020) The role of service quality and perceived behavioral control in shared electric bicycle in China: Does residual effects of past behavior matters? Environ Sci Pollut R 27:24518-24530.

Liu X M, Sun X Y, Wu S J (2019) Evolution of Carbon Emission Game under Dual Governance System: Analysis from the Perspective of Initial willingness Differentiation. Systems Eng $37: 31-47$

Liu Y (2012) An empirical research of awareness, behavior and barriers to enact carbon management of industrial firms in China. Sci Total Environ 425: 1-8. 
Mahmoudi R, Rasti-Barzoki M (2018) Sustainable supply chains under government intervention with a real-world case study: An evolutionary game theoretic approach. Comput Ind Eng 116: 130-143.

Nelson R R (2009) An evolutionary theory of economic change. Harvard university press.

Peng B, Wang Y, Elahi E, Wei G (2019) Behavioral game and simulation analysis of extended producer responsibility system's implementation under environmental regulations. Environ Sci Pollut R 26: $17644-17654$.

Peters M, Fudge S, Sinclair P (2010) Mobilising community action towards a low-carbon future: Opportunities and challenges for local government in the UK. Energ Policy 38(12):7596-7603.

Price L, Wang X, Yun J (2010) The challenge of reducing energy consumption of the Top-1000 largest industrial enterprises in China. Energ Policy 38(11): 6485-6498.

Qu X C, Hou G S, Sun X Y (2019) Evolutionary Game Analysis of Green Innovation Ecosystem of Enterprises under Government Regulation: Analysis from the Perspective of Initial Willingness Differentiation. Systems Eng 37(06):1-12.

Roca C P, Cuesta J A, A Sánchez (2009) Evolutionary game theory: Temporal and spatial effects beyond replicator dynamics. Phys Life Re 6(4):208-249.

Rosa E A, Dietz T (2012) Human drivers of national greenhouse-gas emissions. Nat Clim Change 2(8):581-586.

Shen M H, He Z C (2011) The Experience of Foreign Fiscal Policy on Low-Carbon Economy. Ecological Economy (3),83-89.

Shi M J, Yuan Y N, Zhou S L (2013) Carbon tax, cap-and-trade or mixed policy: Which is better for carbon mitigation? Journal of Management Sciences in China 16(9):9-19.

Shuai J, Cheng X, Ding L, Yang J, Leng Z (2019) How should government and users share the 
investment costs and benefits of a solar PV power generation project in China? Renew Sust Energ Rev 104: 86-94.

Wang C, Shi F (2019) An Evolutionary Game Model for Industrial Pollution Management under Two Punishment Mechanisms. Int J Env Res Pub He 16(15): 2775.

Wang C, Wang W, Huang R (2017) Supply chain enterprise operations and government carbon tax decisions considering carbon emissions. J Clean Prod 152: 271-280.

Wang L, Zheng J (2019) Research on low-carbon diffusion considering the game among enterprises in the complex network context. J Clean Prod 210: 1-11.

Xu R, Wang Y, Wang W, Ding Y (2019) Evolutionary game analysis for third-party governance of environmental pollution. J Amb Intel Hum Comp 10(8): 3143-3154.

Yu X, Jin L, Wang Q, Zhou D (2019) Optimal path for controlling pollution emissions in the Chinese electric power industry considering technological heterogeneity. Environ Sci Pollut R 26:1108711099.

Zhao R, Peng D, Li Y (2015) An interaction between government and manufacturer in implementation of cleaner production: a multi-stage game theoretical analysis. Int J Environ Res 9(3):1069-1078.

Zhao R, Zhou X, Han J, Liu C (2016) For the sustainable performance of the carbon reduction labeling policies under an evolutionary game simulation. Technol Forecast Soc 112: 262-274.

Zhou Y, Bao M, Chen X, Xu X (2016) Co-op advertising and emission reduction cost sharing contracts and coordination in low-carbon supply chain based on fairness concerns. J Clean Prod 133: $402-413$

Zhu Q H, Dou Y J (2007) Evolutionary game model between governments and core enterprises in greening supply chains. Systems engineering-theory \& practice 27(12):85-89. 

regulations based on differential game. J Clean Prod 177:527-546. 